\title{
Using flipped instruction in a technology-enhanced learning environment: the case for scaffolding
}

\author{
Christine M. Witt, California State University, Chico, cwitt3@csuchico.edu \\ Carol Trivedi, California State University, Chico, cltrivedi@csuchico.edu \\ Fariba Aminalroayae, California State University, Chico, faminalroayae@csuchico.edu
}

\begin{abstract}
This article examined the effect of designed conceptual, procedural, and metacognitive scaffolding on team performance during an Enterprise Resource Planning simulation (ERPsim) in the flipped classroom.The scaffolds were embedded in an ERPsim learning unit within a flipped classroom to support student inquiry and team performance. The 120 participants in a randomized control group consisted of undergraduate students enrolled in an introductory supply chain management class designed with flipped instruction. The results revealed that the designed scaffolds had a statistically significant positive effect on the team results during each quarter of the simulation. The results have implications for instructors who use flipped instruction and for technology-enhanced learning environments (TELEs). These results indicate that scaffolding substantially increased the performance of teams. Although flippedinstruction is an engaging teaching methodology, offering students additional scaffolding with flipped teaching can lead to better understanding of course concepts.
\end{abstract}

Keywords: flipped instruction, scaffolding, technology-enhanced learning environment, simulation

\section{Introduction}

Recent research studies discuss the value of flipped instruction for students. The framework of flipped instruction benefits students as they can learn at their own pace outside of class and experience active problem solving and hands-on learning in the classroom (Bergmann \& Sams, 2012). When students are engaged in an inquiry-based flipped classroom, challenge, and question activities lead the students to actively participate in their learning (Aditomo et al., 2013; Kung \& Kung, 2017; Simonson, 2017).

Despite the many learning opportunities provided by flipped instruction, the reality remains that pedagogical methods for teaching within technology-enhanced and flipped instruction environments still need to be researched and refined. The purpose of this study was to investigate the impact of scaffolding in a technology-enhanced flipped classroom environment. Through this study, conceptual, procedural, and metacognitive scaffolding and quantitative methods were used to determine the effects of the interventions on team performance. Team performance was measured by evaluating the quarter results that are similar to a business quarter where at the end of the quarter different metrics of performance are generated for each team playing the ERPsim. The results were based on business performance indicators, such as cumulative net income. Those teams with higher cumulative net income were considered to have performed better in 


\section{Issues in Information Systems}

Volume 22, Issue 2, pp. 52-62, 2021

ERPsim. The insights provided in this study should help researchers and instructors who seek to use ERPsim with their students. The following research questions were analyzed:

- What is the effect of the designed scaffolding on the teams' performance that play ERPsim?

- Will the experimental group that receives scaffolding have a higher cumulative net income than the control group who learn the simulation using traditional methods?

- Does removing (or fading) the scaffolding for the experimental group after the second quarter increases the performance (cumulative net income) of the experimental group?

This paper defines flipped instruction and the ERPsim, examines the background for developing scaffolding in technology-enhanced learning environments, explains the methodology and qualitative analysis, and discusses the findings, conclusions, and recommendations for future research.

\section{Flipped Instruction}

The history of the Flexible Environments, Learner-Centered Approach, Intentional Content, Professional Educators, Progressive Network Activities (FLIPPED), classroom began as early as 1993 when Alison King proposed inverting the class to offer student-centered active learning (King, 1993). In 1997, Eric Mazur developed peer instruction to move the integration of information into the classroom to allow the instructor to coach student learning rather than lecture (Mazur, 1997). More research by Lage et al. (2000) addressed students' different learning styles by creating an inclusive learning environment to flip the classroom in undergraduate economic classes (Lage et al., 2000). Salman Khan used videos to allow students to work at their own pace and review earlier recordings to master course content (Khan, 2012). Khan Academy's use of these techniques has become aligned with flipped learning (Khan, 2012). Bergmann and Sams (2013) developed the flipped master model and suggested that there is no one way to create a flipped classroom (Bergmann \& Sams, 2013). It is dependent on the instructor's styles of teaching and support from the college or university. Most recently, flipped classrooms have extended internationally. Bergmann and St. Clair Smith (2016) established the Flipped Learning Global Initiative with international faculty providing support to schools worldwide with standard practices of delivering training using flipped classrooms (Bergmann \& St Clair Smith, 2016).

In this research study, a flipped classroom was used to motivate students to participate in collaborative, hands-on activities using technology to learn concepts, apply knowledge, and solve problems. The instructor assigns videos, quizzes, and practice activities outside of class to prepare for in-class problem solving and learning (Bergmann \& Sams, 2012; Kung \& Kung, 2017). Based on previous experience with scaffolding, classroom exercises were delivered to enable effective communication and feedback between instructor and student (Chen et al., 2014). When an instructor flips the classroom, it is easier to monitor student progress, encourage the application of course content, and assist students in learning lifelong skills for future career success (Simonson, 2017).

\section{Scaffolding Technology-Enhanced Learning Environments}

Daniela et al., (2018) suggest that students are motivated and have the desire to use technology. However, they require instructors that support their learning by providing meaningful use of technology via scaffolding. This study utilized research on scaffolding to design conceptual, procedural, and metacognitive scaffolds to facilitate student learning during ERPsim. These learning interventions aimed to guide students to identify essential knowledge gaps between what they already knew and what they needed to know to perform and maximize profit during the simulation successfully. Two general mechanisms are described that characterize scaffolding tools (Reiser, 2004). The first characteristic was that software tools could 


\section{Issues in Information Systems}

Volume 22, Issue 2, pp. 52-62, 2021

scaffold student learning in much the same way as interactions with teachers and peers scaffold learning. The second characteristic was that software tools change the way learners approach the learning task.

Conceptual, procedural, and metacognitive scaffolds were defined in 2011 (Kim \& Hannafin, 2011): Among scaffolding purposes, procedural scaffolds guide the student in addressing operational aspects of the learning environment rather than investing cognitive resources in negotiating routine procedures and navigation. Conceptual scaffolds help students identify essential knowledge gaps between what they already know and what they need to know. They guide students' understanding of the problem content, provide support to enhance students' understanding of the problem and related knowledge, and are gradually faded as students negotiate the knowledge and skills needed to solve the problem. Metacognitive scaffolds assist students in assessing their state of understanding, reflect on their thinking, and monitor their problemsolving processes. (p. 408)

Kim and Hannafin (2011) identified critical issues for scaffolding solving problems in classrooms. Through their research, Kim and Hannafin developed a framework that emphasizes "essential dimensions to be considered when teachers scaffold student problem-solving in technology-rich classes" (p. 403). The essential problem-solving activities are problem identification and engagement, evidence exploration, explanation reconstruction, communication and justification of explanation, and revision and reflection of explanation (see Figure 1).

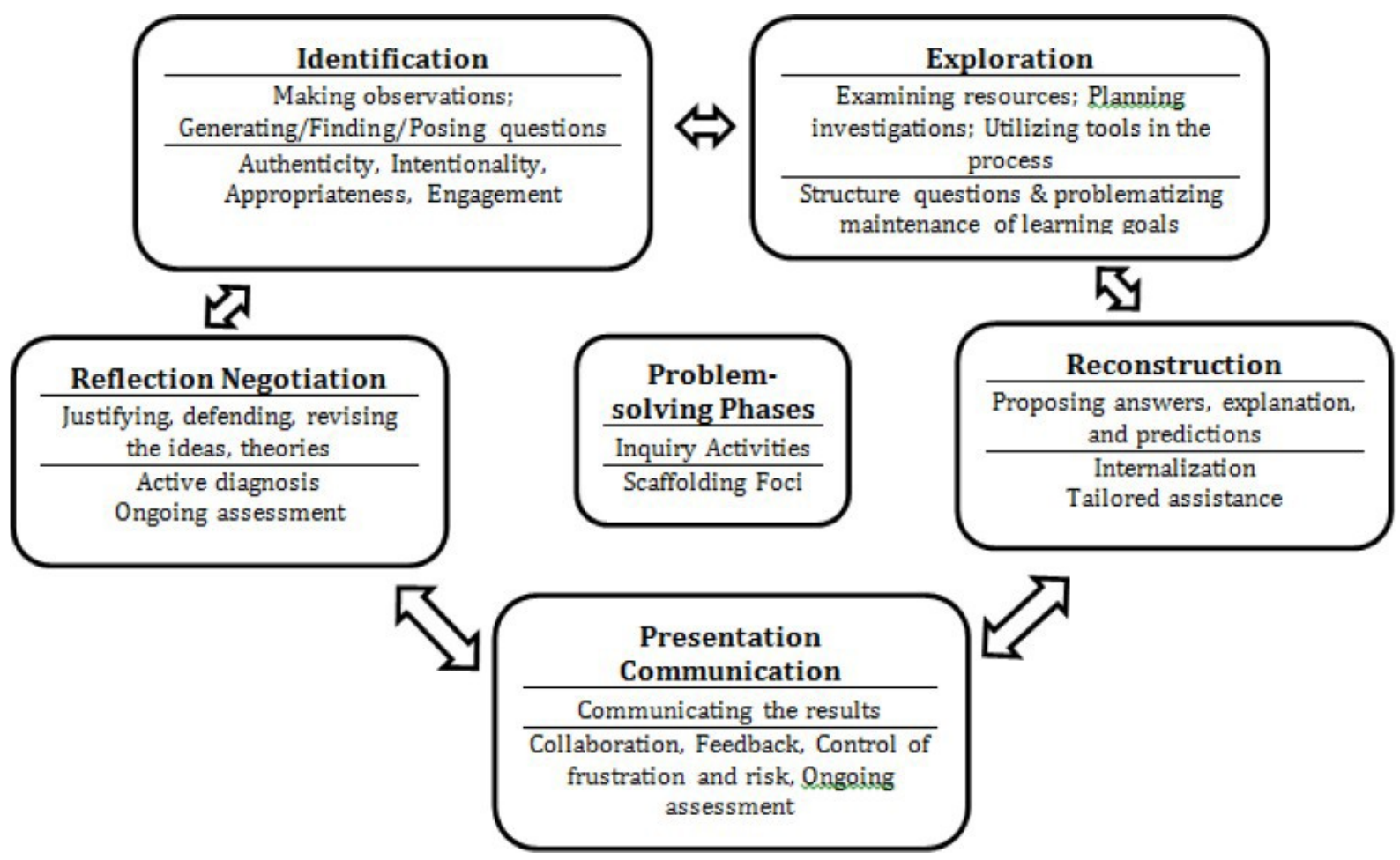

Figure 1. Framework for problem-solving inquiry in technology-enhanced classrooms (Kim \& Hannafin, 2011).

Seminal experts call for continued research and objective data collection into which scaffolds work best in the actual classroom (Azevedo \& Hadwin, 2005; Jacobson \& Azevedo, 2008; Kirschner et al., 2006; Kim 


\section{Issues in Information Systems}

Volume 22, Issue 2, pp. 52-62, 2021

\& Hannafin, 2011; Vygotsky, 1980). This study designed and implemented conceptual, procedural, and metacognitive interventions in a TELE flipped instruction classroom.

\section{ERPsim}

ERPsim is a business simulation serious game that offers the opportunity to research students' learning of complex Enterprise Resource Planning (ERP) concepts through a business simulation. While participating in ERPsim, students compete in teams and navigate an ERP system, SAP (SAP, 2021). ERPsim automates tasks that do not depend on critical business decisions so that students can run the business by focusing on executive decision-making skills such as sales, marketing, procurement, and distribution. The designers of ERPsim at ERPsim Labs state that participating in the simulation would positively influence the learning of Enterprise Systems Management concepts, understanding business processes, and improving skills executing ERP transactions (Léger et al., 2011). ERPsim allows students a chance to revise strategy by playing three different quarters. Thus, students are simultaneously gaining hands-on experience with ERP technology and are solving problems in supply chain management concepts.

In another study of ERPsim, Cronan et al. (2012) concluded that several issues were involved in successfully using ERP simulation games. A similar research study conducted by Cronan and Douglas (2012) yielded positive responses from the participants when polled about their attitudes toward ERPsim. However, Léger (2006) cautioned that students might need additional support during the simulation as they face the many different challenges and varied scenarios presented in other ERP simulation games.

Some of the problems students encounter during ERPsim are significant and can cause cognitive overload and stop team progress. In addition, the simulation interface is SAP, which can be intimidating to students who have not been exposed to the system before playing ERPsim. However, ERPsim leads students stepby-step to navigate and learn SAP through serious gamification.

As with many TELEs, students playing the ERPsim need to think and plan in a complicated integrated way across traditional discipline boundaries. Students need to communicate and collaborate effectively in their assigned teams, understand the individual job responsibilities, and react to changing business realities in real-time scenarios. While ERPsim provided an innovative TELE experience of Enterprise Systems and crossed-functional integration, students were frustrated and confused when they encountered a variety of learning roadblocks during simulation play. At those times, teams required immediate assistance.

\section{Methodology}

This study investigated whether using current research on employing designed scaffolds to support students when they encounter these challenges in a technology-enhanced learning environment (TELE) increased the teams' performance that play ERPsim. Conceptual, procedural, and metacognitive scaffolds were an integral part of the instructional design for the experiment group. The success of these scaffolds in increasing the team performance was compared between experimental and control groups by evaluating the quantitative results at the end of each quarter of the ERPsim student teams played.

The course, Introduction to Industrial Supply Chain Management Technology, was a flipped instruction sixteen-week course at a Midwestern research university. IRB approval was obtained from the institution. This course was designed as a flipped instruction model where lectures and course content are viewed by students online before attending class. A brief introduction to ERPsim was given during the second week 


\section{Issues in Information Systems}

Volume 22, Issue 2, pp. 52-62, 2021

of the semester. The introduction focused on the importance of student understanding of ERP systems and ERPsim for supply chain management candidates as they look at their future careers.

The students in this study were undergraduate students who consisted of freshmen through seniors. Both the control group and the experimental group consisted of 60 students for a total of 120 participants in the study. Each section was comprised of 12 randomly assigned teams. While students played ERPsim, they were placed in randomly assigned teams of five participants. The students remained on the same team for the duration of the study to answer the guiding research questions.

Both the experimental and the control group played three business quarters of the ERPsim Distribution Game. Following the flipped instruction format, the students were required to watch a training video before class. Due to the importance of the content discussed in the training video, both groups viewed the video in class before quarter one of the ERPsim. Both groups participated in the instructor-led discussion of concepts of ERPsim for 10 minutes at the beginning of class, were given 15 minutes to strategize, and then played ERPsim for 20 minutes. For both the control and experimental groups, ERPsim lasted for 60 simulated days and split into three business quarters of 20 days each. The pace of the simulation was 20 minutes for each quarter or one-minute per simulated day.

The control group followed the traditional format outlined in the teaching manual for the ERP Simulation Games (Léger et al., 2011). ERPsim game teaching method, as prescribed by Léger et al. (2011) involved having the students watch the training video, strategize with their team, play the quarter, and then have a class debrief each class on each quarter of ERPsim. These procedures were followed for all three class sessions for the control group. After students viewed the training videos, the instructor answered student questions. After all questions were clarified, the teams in the control group strategized for fifteen minutes before playing a simulated quarter.

Conceptual, procedural, and metacognitive scaffolding assignments were added to the experimental group. This different design was not the usual implementation of ERPsim previously described, in which students view the quarterly videos and play the simulation without a guided assignment. The Quarter One and Quarter Two scaffolding assignments were designed to regulate student learning of concepts presented in the training videos, assist students in understanding the job aid, and help students strategize within their teams to improve performance and achievement while playing ERPsim.

Following the principle of fading as discussed by many scaffolding research studies (Azevedo, 2005) (Kim \& Hannafin, 2011) (Puntambekar \& Hubscher, 2005) (Sawyer, 2006), the students in the experimental group did not receive a scaffolding assignment before the final quarter of ERPsim. Kim and Hannafin (2011) stated that ongoing assessment of student's knowledge is necessary to bridge the gap between what they already know and what they need to know. Scaffolding support should be faded as students learn "to accomplish their problem-solving goals without scaffolds" (Kim \& Hannafin, 2011, p. 408). The scaffolding was removed, or faded, for the third quarter of ERPsim for the experimental group.

A variety of plots, tests, and statistical modeling were used to test the statistical hypotheses identified ( $\mathrm{R}$ Core Team, 2013). The data analysis was completed in $\mathrm{R}$, and a conclusion of whether a significant effect on the team performance was determined from the results of quarters one, two, and three of ERPsim for the experimental and control groups. The lowest ranking team in both the experimental and control group was removed for statistical analysis of all three business quarters because they were not deemed to be alert participants, thus unnecessarily skewed the results. 


\section{Results}

To determine if scaffolding had a significant effect on the teams' performance that played ERPsim, statistical analysis was conducted on the results of the three different quarters played by the control and experimental groups. Because of the nonnormal nature of the data (both in the cumulative net income and the marketing to revenue ratio) and the apparent heterogeneity of variability, traditional t-tests, and ANOVA were not appropriate for comparisons. Thus, comparisons between the two groups were analyzed across three business quarters using statistical modeling after proper transformations of the data.

As shown in Figure 2, the experimental group showed consistently higher medians than the control group in all three-business quarters. The experimental group also demonstrated a more similar result than the control group in all three-business quarters, which also had an extreme outlier in the first quarter.
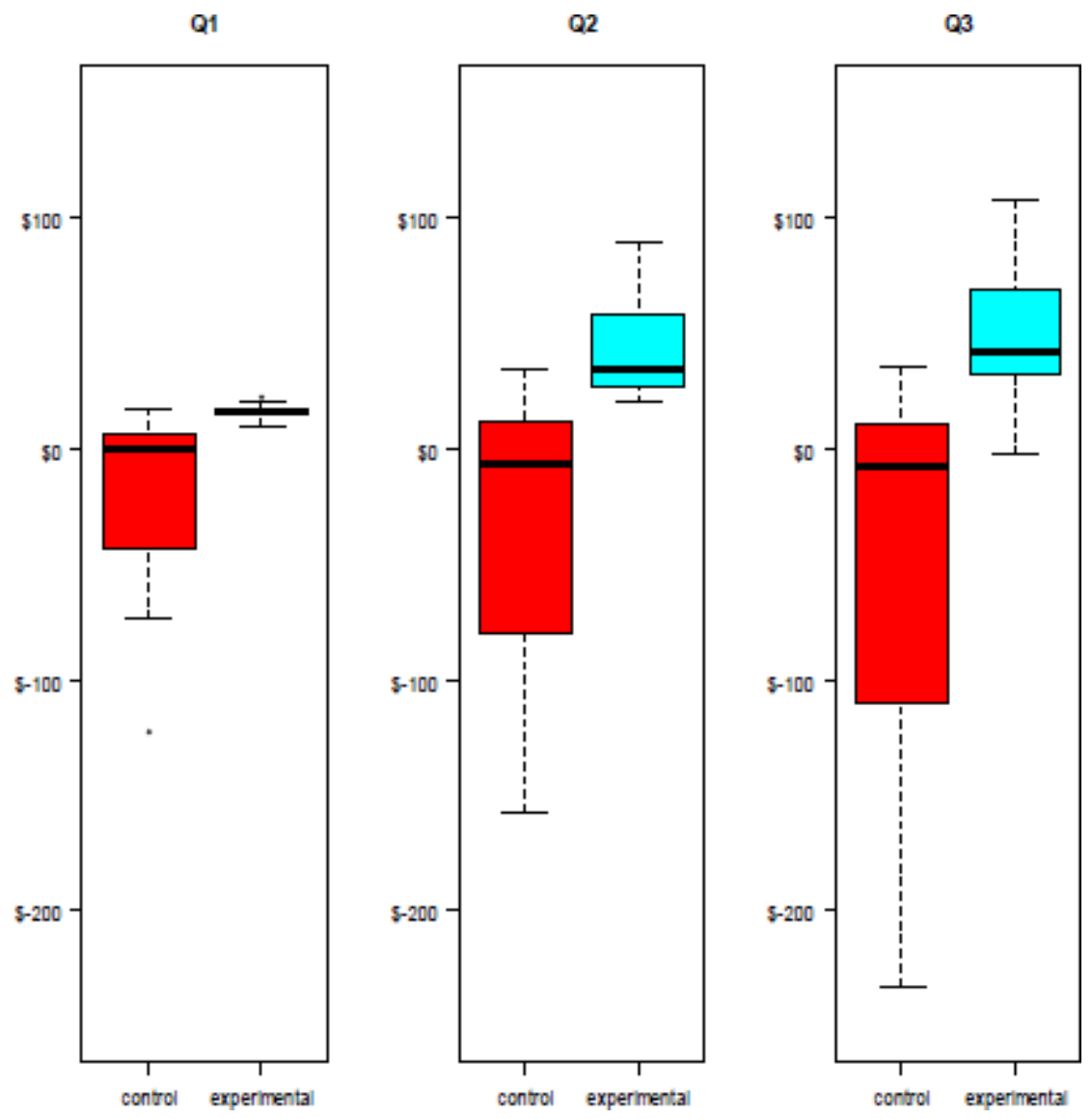

Figure 2. Schematic plot of cumulative net income for the two groups over three business quarters.

More rigorous statistical tests to confirm the significantly different variations between the two groups and across three-business quarters were carried out. The Fligner-Killeen (median) test is one of the many criteria for homogeneity of variances and is considered to be the most robust against departures from normality according to simulation study (Table 1). The Fligner-Killeen test shows a significant difference in variance in the cumulative net income between the two groups (experimental and control) and between the two groups over three business quarters. 


\section{Issues in Information Systems}

Volume 22, Issue 2, pp. 52-62, 2021

\begin{tabular}{lcll}
\hline & $\mathrm{c} 2$ & $\mathrm{df}$ & $\begin{array}{l}\mathrm{p}- \\
\text { value }\end{array}$ \\
\hline $\begin{array}{l}\text { Difference in variance of cumulative net income between the experimental and } \\
\text { control group over the three quarters }\end{array}$ & 5.8723 & 0.0154 \\
\hline
\end{tabular}

Table 1. Fligner-Killeen Test on cumulative net income for the two groups over three business quarters.

Figures 3 displays how the experimental group showed consistently higher means than the control group. The experimental group showed positive and continuously increasing cumulative net incomes over threebusiness quarters. The control group showed consistently negative and decreasing trend in the cumulative net income.

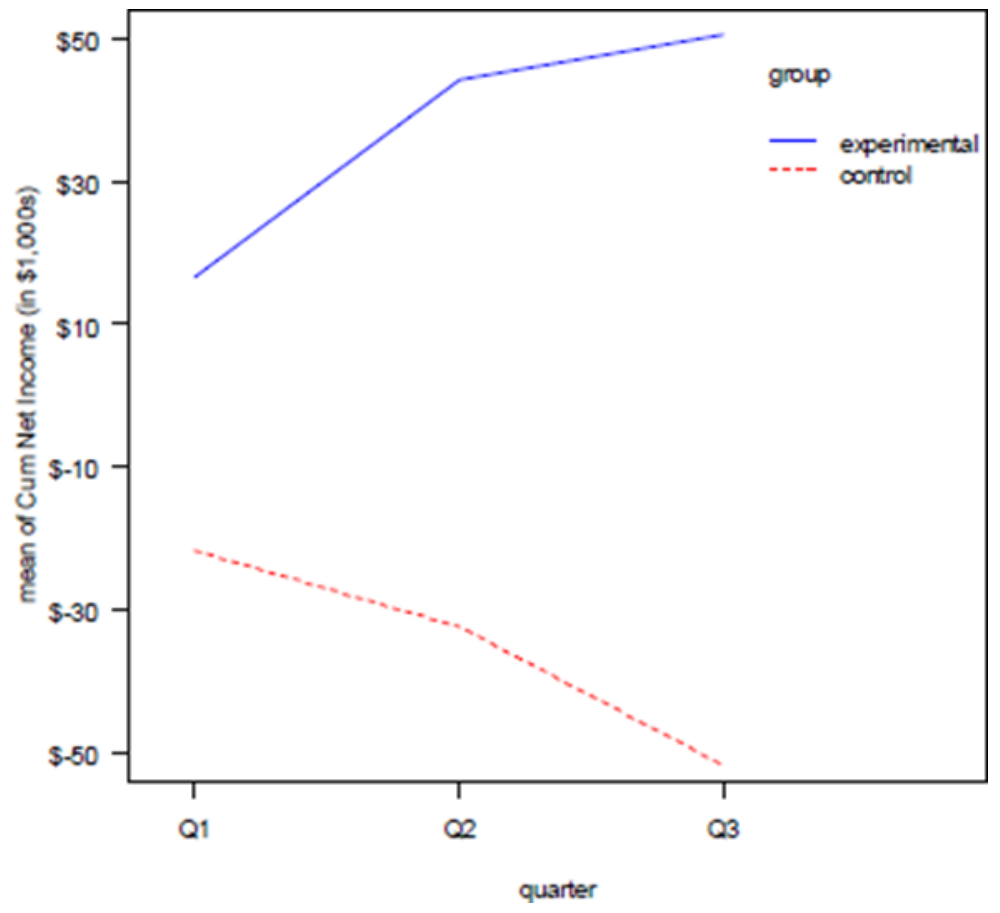

Figure 3. Interaction plot of the cumulative net income for the two groups across three quarters.

\section{Discussion}

The results of the study indicate that the designed scaffolding had a statically positive effect on the experimental group over the course of the entire ERPsim experience. When the scaffolding was removed during the final quarter of the ERPsim, the experimental group continued to show increasing cumulative net incomes. The control group showed a decline in net income throughout all quarters of the ERPsim.

The findings from this study are that scaffolding supports student performance in a technology-enhanced flipped instruction classroom. Students that receive scaffolding in a TELE flipped instruction environment perform at a higher rate than those that do not receive scaffolding. These results align with many research studies of TELEs (Greene \& Land, 2000; Halttunen, 2003; Hmelo \& Day, 1999; Raes et al., 2012; Renties et al., 2012). Instructors should develop scaffolding for TELE that allows learners to 


\section{Issues in Information Systems}

Volume 22, Issue 2, pp. 52-62, 2021

manage their planning and task execution. Students' ability to anticipate and execute essential tasks will enable learners to focus on crucial criteria within the learning environment (Reiser, 2004; Saye \& Brush, 2002).

Conclusions can be drawn that the flipped instruction model without the scaffolding of the TELE was less effective. Students in both the experimental and control groups were engaged in the ERP simulation. However, students learn to absorb and understand the information in various ways and at different individual speeds (Jenkins, 2015). Higher-order thinking skills are needed when students construct their learning using technology to make business decisions (Subramaniam \& Muniandy, 2019). Guiding their learning activities in an organized manner encourages students to participate actively in their learning. The theoretical studies on flipped learning have confirmed the benefits of student-centered learning (Merrill, 2015).

In the spring of 2020, institutions were forced to move to emergency remote teaching due to the COVID19 pandemic. Instructor's classrooms became TELEs overnight. Fryling's (2020) exploratory study found that instructors using a flipped model learning environment moved more smoothly to a fully remote learning environment. As educators look to a future where emergency remote teaching may be necessary for other crises such as additional waves of the COVID-19 pandemic, natural disasters, or political turmoil, developing more flipped classroom environments may benefit both faculty and students (Fryling, 2020). In addition, scaffolding the TELE aspects of a course prior to an unexpected moved to an allremote environment could lead to better student performance.

Readers should be reluctant to draw broad conclusions regarding the effectiveness of scaffolding for individual students, given the fact that the performance results were evaluated according to team performance. This study was limited to an analysis of the team quarterly results of cumulative net income, in particular. The study would have benefited if it had been possible to compare more classes and assign more teams to the scaffolding condition.

\section{Recommendations for Future Research}

Future research should employ a mixed-methods approach. Qualitative research methods may reveal additional insight into the quantitative results. More objective measures should be used to determine if the scaffolding assignments effectively supported students' conceptual understanding of ERPsim. Previous research suggests that student learning-related outcomes are positively influenced by participating in the simulation. Cronan and Douglas (2012) call for research that identifies the main learning characteristics of the ERPsim and analysis of the effectiveness of using the ERPsim in learning. Future studies should measure student knowledge gained from scaffolding TELEs.

Finally, to further research the effectiveness of scaffolding on technology-enhanced conceptual understanding during flipped instruction. Expanding research into how scaffolding TELE flipped instruction can help students achieve high cognitive tasks and critical thinking skills are needed.

\section{References}

Aditomo, A., Goodyear, P. \& Bliuc, A., (2013). Inquiry-based learning in higher education: Principal forms, educational objectives, and disciplinary variations. Studies in Higher Education, 38(9), 1239-1258. 


\section{Issues in Information Systems}

Volume 22, Issue 2, pp. 52-62, 2021

Alammary, A., Sheard, J. \& Carbone, A., (2014). Blended learning in higher education: Three different design approaches. Australian Journal of Educational Technology, 30(4), 440.

Azevedo, R. (2005). Using hypermedia as a metacognitive tool for enhancing student leaning? The role of self-regulated learning. Educational Psychologist, 40(4), 199-209.

Azevedo, R. \& Hadwin, A. F. (2005). Scaffolding self-regulated learning and metacognition-Implications for the design of computer-based scaffolds. Instructional Science, 33(5), 367-379.

Bergmann, J. \& Sams, A. (2012). Flip your classroom: Reach every student in every class every day. 1st ed. International Society for Technology in Education.

Bergmann, J. \& Sams, A. (2013). Flipping for mastery. Educational Leadership, 71(4), 24-29.

Bergmann, J. \& St Clair Smith, E. (2016, July 3). Make no mistake: The flipped classroom is a worldwide phenomenon. https://www.flippedclassroomworkshop.com/the-flipped-classroom-is-aworldwide-phenomenon/

Bishop, J. \& Verleger, M. (2013). The flipped classroom: A survey of the research. [Paper Presentation]. ASEE National Conference Proceedings, Atlanta, GA, United States.

Bodner, G. M. \& Orgill, M. (2007). Theoretical frameworks for research in chemistry/science education. Prentice Hall.

Chen, Y., Wang, Y., Kinshuk \& Chen, N. (2014). Is FLIP enough? Or should we use the FLIPPED model instead? Computers \& Education, 79, October 2014, 16-27.

Cronan , T. P. \& Douglas, D. E. (2012). A student ERP simulation game: A longitudinal study. Journal of Computer Information Systems, 53(1), 3-13.

Cronan, T. P. et al., (2012). Comparing objective measures and perceptions of cognitive learning in an ERPsim a research note. Simulation \& Gaming, 43(4), 461-480.

Daniela, L., Visvizi, A., Gutiérrez-Braojos, C., \& Lytras, M. (2018). Sustainable Higher Education and Technology-Enhanced Learning (TEL). Sustainability, 10(11), 3883. MDPI AG. Retrieved from http://dx.doi.org/10.3390/su10113883

Fryling, M., (2020). From flipped, to flipping out, to mostly sunny: How the flipped classroom model made the move to emergency remote learning less stormy. Issues in Information Systems. 21(1). 281-289.

Greene, B. A. \& Land, S. M. (2000). A qualitative analysis of scaffolding use in a resource-based learning environment involving the world wide web. Journal of Educational Computing Research, 23(2), 151-179.

Halttunen, K. (2003). Scaffolding performance in IR instruction: Exploring learning experiences and performance in two learning environments. Journal of Information Science, 29(5), 375-390. 


\section{Issues in Information Systems}

Volume 22, Issue 2, pp. 52-62, 2021

Hmelo, C. \& Day, R. (1999). Contextualized questioning to scaffold learning simulations. Computers \& Education, 32(2), 151-164.

Jacobson, M. J. \& Azevedo, R. (2008). Advances in scaffolding learning with hypertext and hypermedia: Theoretical, empirical and design issues. Educational Technology Research and Development, 56(1), $1-3$.

Jenkins, J. (2020, January 17). Student perspectives of the flipped learning model. Flipped class. http://flippedclass.com/research-project-john-r-jenkins-ed-d/

Khan, S. (2012). The One World School House: Education Reimagined. 1st ed. London: Hodder \& Stoughton Ltd.

Kim, M. C. \& Hannafin, M. J. (2011). Scaffolding problem solving in technology enhanced learning environments (TELEs): Bridging research and theory with practice. Computers \& Education, 56(2), 403- 417.

King, A. (1993). From sage on the stage to guide on the side. College Teaching, 41(1), 30-35.

Kirschner, P. A., Sweller, J. \& Clark, R. E. (2006). Why minimal guidance during instruction does not work: An analysis of the failure of constructivist, discovery, problem-based, experiential, and inquiry-based teaching. Educational Psychologist, 41(2), 75-86.

Kung, H.J. \& Kung, L. (2017) Flipped Learning Activities for an Introduction to Java Course, Issues in Information Systems, 18(3), 29-39.

Lage, M., Platt, G. \& Treglia, M. (2000). Inverting the Classroom: A gateway to creating an inclusive learning environment. Journal of Economic Education, 31(1), 30-43.

Léger, P. M. (2006). Using a simulation game approach to teach enterprise resource planning concepts. Journal of Information Systems Education, 17(4), 441-448.

Léger, P. M., Robert, J. \& Babin, G. (2011). ERP simulation game: Changing the way we teach and learn ERP systems. HEC Montreal.

Mazur, E. (1997). Peer Instruction: A user's manual series in educational innovation. Prentice Hall.

Merrill, J. (2015). The flipped classroom: An examination of veteran teachers' practices when flipping their classrooms for the first time [Doctoral Dissertation, Texas AM University]. Proquest Digital Dissertations.

Owusu-Agyeman, Y. \& Larbi-Siaw, O. (2018, March 20). Exploring the factors that enhance studentcontent interaction in a technology-mediated learning environment. Cogent Education. https://www.cogentoa.com/article/10.1080/2331186X.2018.1456780

Porter, W. \& Graham, C. (2016). The Institutional drivers and barriers to faculty adoption of blended learning in Higher Education. British Journal of Educational Technology, 47(4), 748-762. 


\section{Issues in Information Systems}

Volume 22, Issue 2, pp. 52-62, 2021

Puntambekar, S. \& Hubscher, R. (2005). Tools for scaffolding students in a complex learning environment: What have we gained and what have we missed? Educational Psychologist, 40(1), $1-12$.

R Core Team, 2013. R-project. (n.d.). http://www.R-project.org

Raes, A., Schellens, T., DeWever, B. \& Vanderhoven, E. (2012). Scaffolding information problem solving in Web-based collaborative inquiry learning. Computer \& Education, 59(1), 82-94.

Reiser, B. J. (2004). Scaffolding complex learning: The mechanisms of structuring and problematizing student work. The Journal of the Learning Sciences, 13(3), 273-304.

Renties, B. et al. (2012). The role of scaffolding and motivation in CSCL. Computers \& Education, 59(3), 893-906.

SAP, (2021). SAP. (n.d.) https://www.sap.com/corporate/en/company.html

Sawyer, R. K. (2006). The Cambridge handbook of the learning sciences (2 ed). Cambridge University Press.

Saye, J. W. \& Brush, T. (2002). Scaffolding critical reasoning about history and social issues in multimedia- supported learning environments. Educational Technology Research and Development, 50(3), 77-96.

Sharma, P. \& Hannafin, M. J. (2007). Scaffolding in technology-enhanced learning environments. Interactive Learning Environments, 15(1), 27-46.

Simonson, S. (2017). To Flip or Not to Flip: What are the Questions? Education Sciences, 7(71), 1-10.

Subramaniam, S. \& Muniandy, B. (2019). The effect of flipped classroom on student's engagement. Tech Know Learn, 24, 355-372.

Vygotsky, L. S. (1980). Mind in society: The development of higher psychological processes. Harvard University Press. 